\title{
Supporting Group Coherence in a Museum Visit
}

\author{
Lesley Fosh, Steve Benford, Boriana Koleva \\ University of Nottingham \\ Nottingham, UK \\ [firstname.lastname]@nottingham.ac.uk
}

\begin{abstract}
Visiting museums as part of a group poses the challenge of managing engagement with exhibits while preserving group cohesion. We respond to this by reconfiguring the social dynamic of visiting with an experience designed specifically for groups, that invites the group members themselves to design and 'gift' interpretations to one another. We present a trial of this experience with groups of family and friends at a museum. We show how groups managed and configured themselves during the visit, revealing the strategies involved in maintaining different group behaviors. We discuss how our design accommodated different visiting styles by making objects social and scaffolding rather than directing the group experience. We interpret our findings to frame group coherence as a flexible and configurable phenomenon within CSCW.
\end{abstract}

\section{Author Keywords}

Museums; collaboration; visiting; mobile guides; gifting; groups; coherence.

\section{ACM Classification Keywords}

H.5.m. Information interfaces and presentation (e.g., HCI): Miscellaneous.

\section{INTRODUCTION}

It is well documented that when most people visit museums, they do so as part of a group of friends, family or loved ones, and the social experience can be a key motivation for visiting in the first place [8]. In response, there has been a shift from technology for personal use, such as traditional audio guides, to those that support collaborative interaction between visitors, enhancing the visit by supporting the collaborative making of meaning [12], connecting visitors with each other over content [5], or promoting collaboration with tabletop exhibits [11].

Permission to make digital or hard copies of all or part of this work for personal or classroom use is granted without fee provided that copies are not made or distributed for profit or commercial advantage and that copies bear this notice and the full citation on the first page. Copyrights for components of this work owned by others than the author(s) must be honored. Abstracting with credit is permitted. To copy otherwise, or republish, to post on servers or to redistribute to lists, requires prior specific permission and/or a fee. Request permissions from Permissions@acm.org.

CSCW '16, February 27-March 02, 2016, San Francisco, CA, USA Copyright is held by the owner/author(s). Publication rights licensed to ACM.

ACM 978-1-4503-3592-8/16/02 ..\$15.00

DOI: http://dx.doi.org/10.1145/2818048.2819970
Other research has considered how groups of visitors behave. Studies have uncovered the many different types of groups that visit museums [16] and the types of interactions that occur, for example the roles parents take on when visiting with their children $[15,19]$, and how goals such as learning and coordination of the visit might be supported by collaborative systems.

In spite of this growing body of work, there is recent evidence that supporting group visiting remains challenging for CSCW. Tolmie et al.'s ethnographic study of two very different museums uncovered a phenomenon that appeared to span across many types of small groups [28]. Tolmie repeatedly observed visitors' engagement with exhibits and information being prematurely interrupted because of a need to maintain a physical coherence within the group. Tolmie et al.'s work suggests that groups of visitors struggle to simultaneously manage engaging with museum content on the one hand, while 'sticking with' or otherwise tending to the needs of fellow group members on the other, often being 'dragged away' from exhibits and information because of a desire to catch up with group members who are moving on at a faster pace.

A proposed solution was to reconfigure the social dynamic of visiting, perhaps by designing for more collaborative experiences or increasing visitors' awareness of each others' activities. Tolmie suggests that one way of making visiting more collaborative might be through 'gifting' experiences of objects, such as by sharing recommendations or interpretations. This approach was explored in a study by Fosh et al. of pairs of adults visiting a contemporary arts museum, where one member of each pair was invited to design a personal tour for their partner [10]. Fosh et al. found the approach to be promising in giving visitors intensely personal yet shared experiences around objects. It was reported, however, that visitors often felt a degree of social discomfort, perhaps due in part to the unmet 'obligation to reciprocate' inherent to gift giving rituals, since the approach offered no opportunity for gift recipients to reciprocate with a gift of their own, hence the gifting relationship between giver and recipient was imbalanced. They also reported on the intensity of the one-to-one pairwise interaction between participants and the visible presence of the designer, who was often anxious about how their design would be received.

In this paper, we extend Fosh et al.'s approach to accommodate more diverse and mainstream visiting groups, i.e. moving from pairs to small groups, and to directly 
address the challenges of group visiting identified by Tolmie et al. in the design of a group visit. Our aim was to enable small groups, typical of those that visit many museums, to be able to share an experience in which they can enjoy focused engagement with artifacts and interpretation while also paying attention to and meeting the needs of different group members.

We firstly describe how we extended the approach and worked with groups of visitors to realize it in a formative user study. Our study explores how visitors flexibly coordinate their visit amongst themselves to accommodate different individual and group visiting styles. We then discuss the design features that support these different styles and what it means for group coherence.

\section{APPROACH}

We now describe the design of our group visiting experience and its deployment in a formative study. Following an 'in the wild' strategy [6], we worked with a particular museum exhibition to design an extended visiting experience and then deploy it with groups of visitors. We conducted a naturalistic study through observations and interviews to build up a rich case study.

\section{Setting}

The setting for the experience was Nottingham Castle Museum and Art Gallery, a traditional art and local history museum set on the site of Nottingham's Medieval castle. Among the various exhibitions in the museum - fine and decorative arts, local history, archaeology and temporary contemporary art exhibitions - we chose to focus on the exhibition named 'Every Object Tells a Story', a collection of decorative, historical and functional objects that, through our conversations with the museum's curators, we learnt was a collection that groups of visitors often struggled to engage deeply with, perhaps due to the large number of exhibits presented in glass cabinets and the largely functional nature of the objects. We felt this provided a challenging setting for testing the approach. The exhibition covers two mid-sized rooms adjacent to each other.

\section{Content and experience design}

The experience spanned two distinct stages of participation. First, visitors attended a design workshop where they put together the content for their group's experience. Next, they were invited back to the museum on a separate occasion to use the experience on a group visit. Our overall experience was based on Fosh et al.'s gifting approach that saw one member of each pair of participants design a personalized experience for the other. Our first challenge was to scale the approach up to cater to groups larger than two. This involved working out who would design and gift content, who would receive content and how it would be presented:

Gifting configuration. Fosh et al. found that designing and gifting an experience was often more beneficial than receiving one, giving the designer the chance to develop and revisit an interpretation through experiencing it with their partner. We therefore felt that each group member should get a chance to design interpretations as well as experience them. Gifting is highly ritualized and the literature tells us that when multiple people are involved, gift-givers are concerned about mutuality and equipollence, the absence of which can cause anxiety [31]. Our extended gifting model thus allowed each member of the group to design an interpretation for each other member, as shown in Fig. 1. For example, in a group of four friends, each person would pick out three objects - one for each of the other member of the group. The tour would then consist of twelve objects.

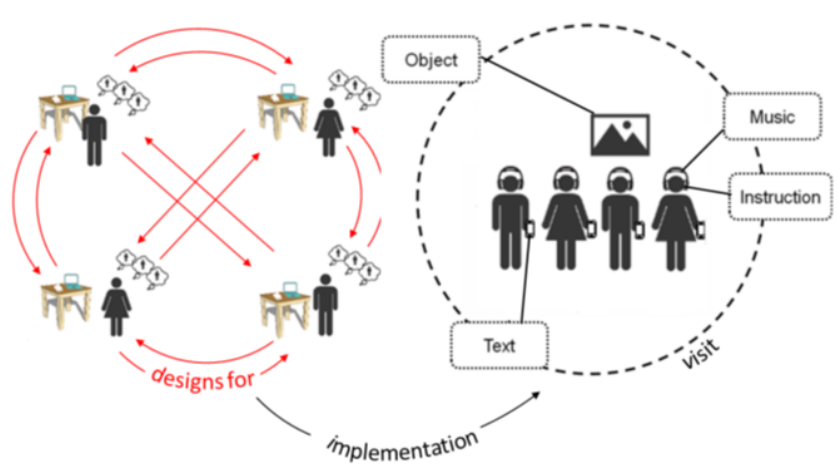

Figure 1: Model of gifting in a group of four. Red arrows denote an interpretation is designed and gifted from one person to another. Right side of figure represents one interpretation.

Content. The participants were able to design the interpretation resources that would be delivered through the mobile guide to accompany the objects in the tour. They were able to choose three pieces of content to fit our experience template [9]:

- a piece of music (to suggest a theme, mood or tone);

- a vocally recorded instruction for how to interact with the object (performing a physical action or looking in a particular way); and

- a portion of text to be presented as they walked away (information or a personal message).

In replication of Fosh et al.'s study of this approach between pairs, we encouraged participants to use the choice of object and resources to design a personalized interpretation for one another, perhaps communicating a particular message or viewpoint alongside or in place of the more traditional museum interpretation. We placed no restrictions on the objects they could choose, nor the content they chose to accompany them. There were no constraints on overlap of choices or otherwise. The instructions were recorded by a voiceover artist and played alongside the audio track while the text was presented on the screen once the audio had finished.

Presentation. The gifting literature tells us that gifts are experienced as a social occasion, and are often exchanged in the presence of others. Onlookers - those present who 
aren't giving or receiving - play a key role in gifting occasions. When gifts are received, they are often presented to onlookers for assessment, and onlookers respond with positive evaluations of the gift and sometimes questions [21]. It was therefore decided that each member would be able to engage with the entire set of content, not just the parts that had been designed for them, to allow participants to take on the role of onlookers, as they would in traditional gifting occasions. This also ensured there would be more content for everyone to try and potentially less confusion around who is doing what. The objects were presented in a list based on where they would be found in the museum space, suggesting an order in which to visit the objects but not enforcing it; it was possible to deviate by selecting objects out of order.

A further design feature intended to support group visiting was to conceal the identity of those who an experience was designed by and for until after the content had been delivered. We anticipated that by only revealing the identities of the designer and recipient towards the end of the experience, an element of fun and expectation was introduced as participants undergo a process of 'working out' who the object was for and from, while keeping them engaged to find out whether or not it was designed for them - providing an incentive to see the experience through to the end. Our rationale was also that instead of each group member seeking out their own content, they could all engage with the same full set of content.

\section{Participants}

We recruited a total of 41 participants through our University's network and the museum's mailing lists. We recruited a total of twelve self-organized groups: six groups of adult friends and six families consisting of one or two parents and one or two children. Each group had three or four members who had formed a group prior to attending the study. Our decision to work with these small groups was based on the types of group that commonly visit museums $[8,19]$, and to ensure the design and visit process was manageable. All participants were interested in visiting museums either as a leisure activity, out of academic interest, or both.

\section{Workshops}

Each group was invited to the museum to attend a two-hour long workshop where they were able to self-design a custom mobile tour of the museum's objects. The group members were given a set of worksheets that guided them through the process of choosing objects, music, instructions and text. They were given access to the Internet to look up information and listen to music options.

\section{Visits}

The participants were invited back to the museum in their groups to use their tours, which had been implemented onto Android smartphones using the AppFurnace tool [2]. The interface presented them with a complete list of all the objects chosen by the group in the design session (Fig. 2a). Once selected, the participant is instructed to locate the object and prepare to start the experience (Fig. 2b). The music and vocally recorded instruction are played through a set of headphones, before the music fades out after 1-2 minutes. The portion of information is then presented as text on the screen along with a 'label' showing who the object was chosen for and who it was designed by (Fig. 2c).
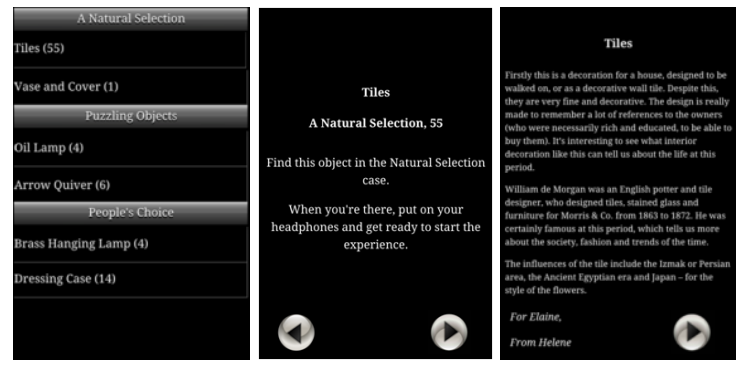

Figure 2: Screen shots - a) list of objects, b) set up and c) text.

\section{Data collection and analysis}

We initially captured participant's written designs and justifications from the worksheets as well as audio recordings of the workshops in order to understand how they went about the design task. We video recorded the groups of participants using the experience in the museum to capture an overview of their interactions, and used wireless microphones to capture their conversations. Once they had finished using the experience, we conducted semistructured interviews with the groups, asking them to reflect on each of the designs and the experience as a whole.

Our approach to analyzing the video data was to adopt an ethnographic style across a number of data sessions, reviewing each group's interaction with the museum content, the mobile technology, and each other. We summarized an overview of what happened in each interactional sequence, based on our analysis of participants' gaze, gestures, utterances and interactions with relation to the designed content. While no two sequences were the same due to the different objects visited and the bespoke content delivered, we were able to draw out behaviors that were broadly characteristic of how different groups approached their visits. These sequences were further analyzed and transcribed in detail to draw out how the sequential order of their activities related to the gifted content they were engaging with, including how the gifting relationship for each portion of the experience affected the participants' behavior. Our interview data was used in conjunction to explain what we saw, with participants elaborating on what they thought and did at each stage of the visit. In taking this approach, we were able to build a rich case study of each groups' engagement with our experience from start to finish. 


\section{FINDINGS}

We present our findings with a primary focus on how the visitors organized their group experiences of using the mobile guide. We firstly provide a general overview of the groups' makeups and how they approached the design of their experiences. We then present a representation of how the group visits were organized, before looking in detail at a set of examples where the key themes that typify the social organization of the visit are made manifest.

\begin{tabular}{|c|c|c|c|}
\hline Group & Adults & Children & Relationship \\
\hline 1 & $1 \mathrm{M}, 2 \mathrm{~F}(24-28)$ & - & Friends \\
\hline 2 & $3 \mathrm{M}(27-28)$ & - & Friends \\
\hline 3 & $1 \mathrm{M}, 3 \mathrm{~F}(65-70)$ & - & Friends \\
\hline 4 & $3 \mathrm{~F}(20-24)$ & - & Friends \\
\hline 5 & $3 \mathrm{~F}(25)$ & - & Friends \\
\hline 6 & $1 \mathrm{M}, 3 \mathrm{~F}(28-29)$ & - & Friends \\
\hline 7 & $1 \mathrm{M}, 1 \mathrm{~F}(35,37)$ & $2 \mathrm{M}(7,10)$ & Family \\
\hline 8 & $1 \mathrm{M}, 1 \mathrm{~F}(36,37)$ & $2 \mathrm{M}(3,6)$ & Family \\
\hline 9 & $1 \mathrm{M}, 1 \mathrm{~F}(35,36)$ & $2 \mathrm{M}(7,8)$ & Family \\
\hline 10 & $1 \mathrm{~F}(34)$ & $2 \mathrm{~F}(4,6)$ & Family \\
\hline 11 & $1 \mathrm{M}, 1 \mathrm{~F}(37,38)$ & $1 \mathrm{M}(6)$ & Family \\
\hline 12 & $1 \mathrm{M}, 1 \mathrm{~F}(39,40)$ & $2 \mathrm{M}(7,8)$ & Family \\
\hline
\end{tabular}

Table 1: Groups and their members $(M=$ male; $F=$ female $)$.

\section{What they designed}

The design process first involved browsing the exhibition, looking at objects to draw inspiration, until the participant found a suitable match between their knowledge of the person they were choosing for, their own ideas for a particular theme, the properties of the object itself and how they interpreted the object. Music was often used to reflect themes brought up by the object or to set a particular mood or emotional tone. The music choice tended to be a piece that was known and liked by both the designer and recipient, and matched the interpretation the designer wanted to get across. Some participants drew inspiration directly from the object, choosing, for example, a traditional piece of music from the era or culture the object belonged to, which was the case for a visitor in Group 1 who chose to set a Japanese arrow quiver to a piece of traditional Japanese music.

The choice of instruction was also used to set an emotional tone for how the object would be experienced. Again, the inspiration for the specific instruction came from the object's properties, the intended theme or type of experience and the participant's interpretation of the object. Instructions included to "Strike a pose, like one of the chess pieces" (for a chess set chosen by the mother in Group 9 for her son), and to "Pretend you are at a grand tea party, and think about all the rich and pretentious people you'd meet" (for a tea caddy chosen by a member of Group 4).
Finally, the text, to be displayed after the music and instruction, was used by participants to wrap up the experience, delivering factual information they had found about the object or explaining their interpretation or reason for choosing it. It tended to follow on from the other resource choices - for example, a child in Group 7, after instructing his father to think about what an object was used for, chose to explain "This curved spike was twisted into the elephant's hide to make it behave in a certain way. I thought that you would put a piece of fruit on the spike to tempt the elephant to go in different directions, as the elephant would respect you more." Text was also used to deliver personal messages, for example, "I feel this sums up a part of your character and is a nice object to link our friendship."

\section{Adapting the gifting model for families}

Three of our six family groups (7, 8 and 12) chose to reconfigure themselves into subgroups to complete the design task, for example splitting into two parent-child teams. The members of the subgroups were then able to help each other with their designs, with the parents generally overseeing the process and the children given control over the specific content. This approach proved successful in keeping the children on task and generating ideas, although it should be noted that the groups who did not team up were also successful in completing the design. One observation we did have was that, at times, one partner's ideas would dominate the design - e.g. in Group 8 , the mother and son working on a design for the other son chose a Gujarati child's jacket and instructed to 'Imagine wearing something that makes you feel warm, loved and comforted', which the mother reported reflected her memories of looking after her son when he wore very small clothes. In this instance, the design was framed as being from the mother and son, i.e. they produced one design between them for the recipient. In other cases of two participants teaming up, they produced a design each but helped with each other's designs.

The child in Group 7, who worked on his own, used the design to relate a decorative knife blade to his father's background in the military, something that the father was surprised by and described as "really touching" once he came to try out the experience. Of course, the ages of some of our younger participants put a limit on how much they could design independently.

\section{Returning to use the experience}

Our approach required groups to return to the museum when their designs had been implemented (by us) into a mobile guide. Groups took between two days and two weeks to return for their second visit. One of our family groups, Group 12, was unable to return within the timescale of our study so did not get to try out their experience. One member of Group 5 was also unable to return to use her experience, but the remaining two friends completed the full experience nonetheless. 


\section{Organizing the group visit}

All group members received the same set of objects regardless of who designed for whom - they were then free to choose whether to experience them all together or not. The interface to the guide suggested an order by presenting the set of objects in a list based on where they would encounter them in the museum. However, this order was not enforced, so groups could choose to visit objects in a different order, and decide whether to follow the order together or choose a separate order individually.

From analyzing our video recordings we were able to determine which objects group members visited across the duration of their visit. Figure 3 provides a summary timeline documenting the time visitors spent visiting the objects in their experiences and the extent to which it was coordinated among members. We were able to judge when participants were visiting an object from our video recordings, specifically participants' orientation, gaze, wearing of headphones and interaction with the device.

For each group's timeline, a single row represents an individual group member, while the time in minutes (from the beginning of our video recordings) is noted along the horizontal axis. The time spent visiting objects is represented by the horizontal lines and numbers; the numbers denote the object's suggested order in the experience. The dashed horizontal lines show times when it was not possible to capture the visitor's exact movements often due to the limitations of using only one video recorder to record multiple participants.

Our timelines show an overview of how the different groups organized their visits - which visitors were grouped together at different points of the visits. One approach, as displayed by groups $1,5,7,9,10$ and 11 was to stay together for the entire visit, visiting the same object at the same time, and following the order suggested by the guide. At the other extreme, members of groups 2, 4, 6 and 8 visited objects separately or in subgroups, deviating from the suggested order and only crossing paths coincidentally. Group 3 showed a range of behaviors, often staying together but sometimes separating before coming together.

The timelines also show that it wasn't always the case that experiences were encountered with both the designer and recipient present at the same time. While those who stayed together were able to discuss, comment on and assess the objects as experienced, those who visited objects separately were not able to exchange such immediate feedback.

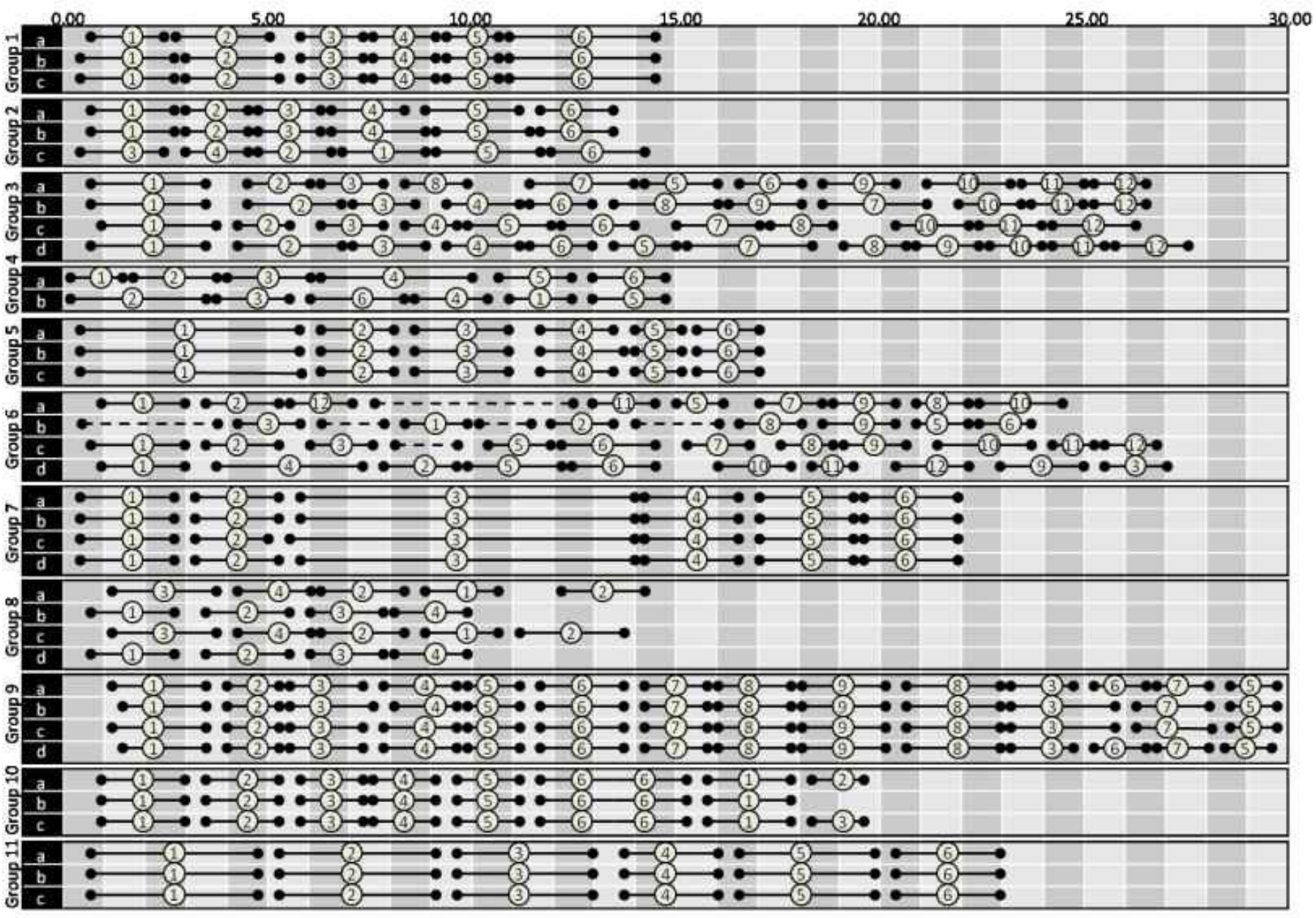

Figure 3: Timelines showing group members' engagement with objects over time. 
Our video observations and subsequent interviews tell us that all but two visitors fully completed the experience visiting all of the objects including those they had designed, those designed for them and those designed by others for others. One visitor chose not to visit the objects that she had chosen, stating afterwards that she was "embarrassed" that her text explanations were more detailed than others', reflecting the large amount of thought that she put into her designs and her anxiety at how they would be received. Our youngest participant, aged three, did not engage with the experience himself but was shown parts of it by his father. All visitors who did engage with the experience listened through to the end of the audio (music and instruction) before disengaging, and most visitors appeared to follow the instructions that had been designed. There was often evidence of visitors working out who the object had been chosen for part way through the experience - one commented sarcastically, "Oh I wonder who this is for" and sharing reactions to finding out the relationship at the end - for example, "That was for me", offering thanks and praising the designs.

Unsurprisingly, the highest levels of social contact were between those visitors who stayed together during the visit. These visitors engaged with each other to navigate between objects, coordinate starting each experience, share reactions and reflect on the interpretation. However, we were also able to observe social contact between those visitors who chose to visit objects individually. Sometimes this happened in the form of chance encounters, such as when two or more visitors find themselves at the same object without having consciously coordinated it, but there were also occasions where visitors deliberately initiated contact by greeting one another, asking questions, sharing reactions and asking questions. Some of the groups that split up spent significant portions of their visits in different rooms of the exhibition and out of line of sight, but they would often come back into each others' visual fields at some point, and often coordinated coming together at the end of the visit.

Our overall impression from the video observations is that visitors were able to organize a structure for their group visit, and were generally able to maintain a level of sociality in any case. Nearly all participants did all of the content, and when they did, they listened through to the end of the audio and followed instructions. We observed much acknowledgement, appreciation and comment, sometimes at exhibits and sometimes on encounters between.

\section{A CLOSER LOOK}

We now consider more closely the work involved in organizing a group visit with our experience. For those groups that stayed together, how did they manage their continued shared engagement? For groups that separated, how did they manage disengaging and coming back together? We focus on a series of vignettes to illustrate how these various issues played out during the visit. Three key group behaviors are identified: sticking together, splitting up and drifting apart.

\section{Sticking together}

We now look at what was involved for those groups that chose to stay together for the visit.

Example 1: Group 5. This group of three female friends designed a tour of six objects of historical and cultural interest. Their approach to organizing their visit was to visit each object together in the order suggested by the guide. They begin the experience by entering the gallery at a slow pace, looking around as they prepare to engage with the experience.

A: Er, which one do you, er? ((Holds device in front of her, Fig. 4a))

(3.0)

B: We could do it in the ((gestures to device, Fig. $4 b))$

C: ((looks at $A$ and $B$, nodding $)$ )

(...)

$A$ : In the order

B: Yeah

A: Oh. Natural selection (Clooks towards the display case 'Natural Selection'))

A: ((stands to left of object))

$B$ : ((stands to right of $A)$ )

C: ((stands to right of $B)$ )

$(C A, B$ and $C$ listen to the audio and look at the object, Fig. 4c))

(2.07)

B: ((looks at A, Fig. 4d)) It's Egyptian?

This fragment sees A and B jointly deciding to visit the objects in the order suggested by the guide. They choose and arrive at the first object of their experience, a set of earthenware tiles chosen by $\mathrm{A}$ for $\mathrm{C}$. They arrange themselves in a semi-circle around the object where they stay while they listen to the audio designed by A. B, the intended recipient of this design, then queries $A$ on the interpretation she designed for $\mathrm{B}$. The fragment continues with B asking, "can we play it again?" and going on to redo this experience, while $\mathrm{A}$ and $\mathrm{C}$ wait for her to finish before moving on.
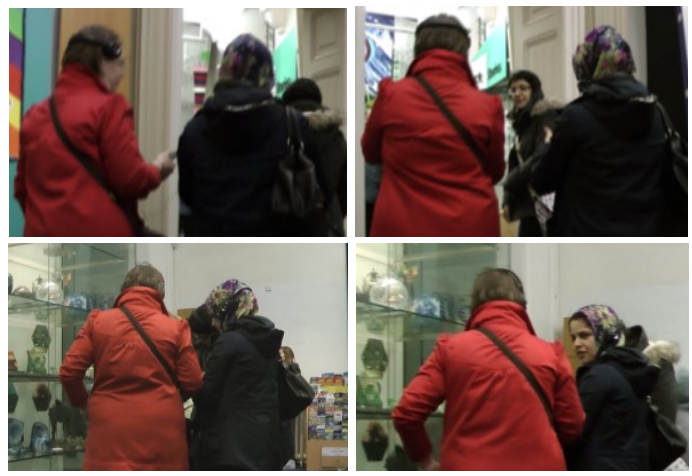

Figure 4: Group 5 a) and b) (top) navigating towards the first object; c) and d) (bottom) at the object.

Example 2: Group 7. While it was most common for families to stay together during the visit, there was significant work involved in managing the children's visit. It was common for one of the parents to take a commanding 
role to ensure all members of the family stayed together and did not move on prematurely.

Group 7 is a family of four with a mother, D, father, E, and two sons (F, aged ten and $\mathrm{G}$, aged seven). In this example, they are visiting their second object, a Japanese sword displayed in a glass cabinet.

D: ((Reading from device)) which was polished to look very impressive.

$D$ : So all that [G], see all the bobbly bits ((pointing to the object, Fig. 5a)) (...) that's actually fish skin, ray- ray skin, that's amazing isn't it? (...) so it's actually fish skin in there that's covering the sword hilt. Can you see? $\mathrm{F}$ : who did the Chinese roof tile? (...) And where is it?

E: Don't know.

D: It's got to be here again, hasn't it?

G: Oh (.) I I I know, I know where that is (Clooks towards the next object))

$\mathrm{F}$ : ( (Walks towards the object and points at it, Fig. 5b))

G: It's there ((points to the object, Fig. 5c))

E: object Stories ten, oh yeah (...) oh right.
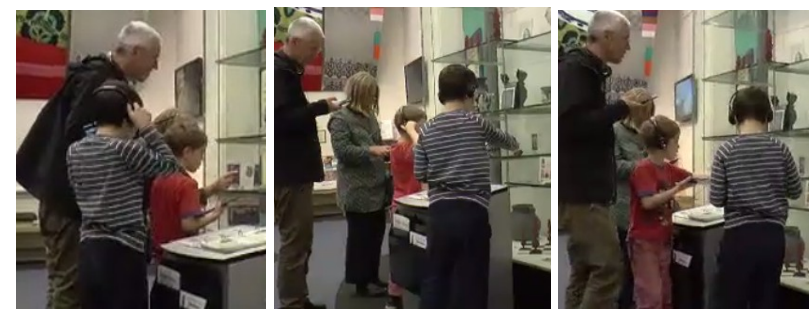

Figure 5: Group 7 (a) D pointing out fish skin; (b) F finding the next object; (c) G pointing out the object

The above fragment shows the mother's efforts to ensure both children engage with the experience: reading the text for them, checking they have read and understood the content, and even rephrasing the information. Meanwhile, F He waits until his mother reaches the end before signaling he is ready to move on: "Who did the chinese roof tile? (...) And where is it?" He begins looking and finds it on his own, but G, who chose the object, also moves to point it out, and they all move on to look at the tile.

\section{Splitting up}

Other groups were less concerned with staying together for the visit, with some group members actively seeking out their own paths through the museum, as shown in our next examples.

Example 3: Group 6. In this example we see four friends, who have all known each other for around eight years. They chose a range of objects and their designs were often playful, fun and with personal meaning. In this fragment, each of the four visitors is at a different stage of the visit, having chosen to visit objects separately and in different orders. J and $\mathrm{K}$ arrive separately at the same object, a set of duck-shaped weights chosen for $\mathrm{J}$ by $\mathrm{H}$. The instruction for this object is to follow a stranger around the gallery. As we join them, $J$ and $K$ are both coming to the end of the experience, having listened to most of the audio.
J: ((Looks around at K, Fig. 6a)) Ha ha ha. (...) I didn't do it, did you do it?

$\mathrm{K}$ : No I couldn't find anyone to chase but it did make me laugh.

J: Yeah.

K: It would've been perfect 'cause 1ike, I'm finding that (...) it's better to have something to do while the music's playing.

J: Yeah it would be good I think if you could read as the music's playing.

K: Yeah.

J: I know what you mean, yeah.

K: ((reads device, Fig. 6b)) (h)That's s(h)o good. Th(h)at's really good though, I love it. The whole thing's great. Yours are really good, mine, I don't think mine are like (...) um (.) I can't think of the word for it, I' 11 have to think of the word for it.

$\mathrm{H}$ : ((Approaches $\mathrm{J}$ and $\mathrm{K}$ from behind, Fig. 6c))

K: Mine aren't um=

H: [Did you like it?

$\mathrm{K}:=[$ Connecting

J: It was great, yeah, it was so good.

K: It was really good.

$\mathrm{H}$ : Ha ha ha ha ha ha ha.

K: Love it ((turns to face H, Fig. 6d))

J: Heh heh heh. That's amazing.

$\mathrm{H}$ : Did you follow someone around?

J: No.

$H:$ WHAT?

J: I looked around but then I was really embarrassed.

$\mathrm{H}$ : I did it.

K: No one was walking though I just walked instead by myself.

$H$ : I walked (h)behind (h)a str(h)anger. Ha ha ha.

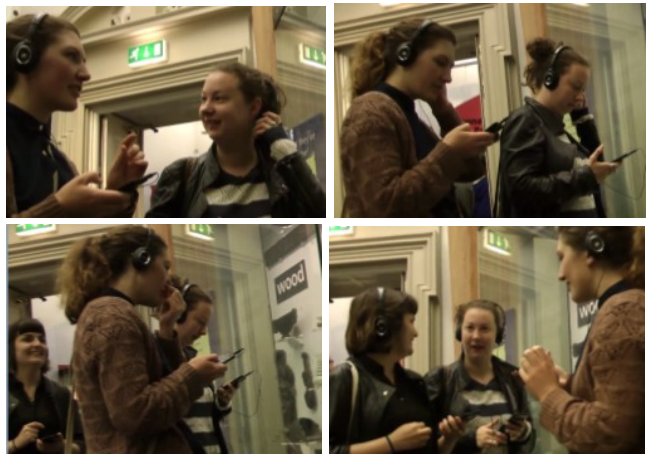

Figure 6: a) $\mathrm{K}$ and $\mathrm{J}$ (l-r); b) $\mathrm{K}$ and $\mathrm{J}$ (l-r); c) $\mathrm{H}$, $\mathrm{K}$ and $\mathrm{J}$ (l-r); d) $\mathrm{H}, \mathrm{K}$ and $\mathrm{J}$ (l-r).

Despite visiting separately, the visitors in this example were able to share experiences of objects, either when finding themselves at the same object without having expressly coordinated it ( $\mathrm{J}$ and $\mathrm{K}$ ) or by noticing when someone has visited a particular object and approaching them for feedback, as $\mathrm{H}$ did here with the object she designed for $\mathrm{J}$. $\mathrm{K}$, neither the gifter or recipient of this experience, joins in with assessing the experience while distinguishing between others' gifts and her own: "yours are really good".

Example 4: Group 8. The one family group that did split for the experience was Group 8. They start the experience with the father of the family, M, carrying the three year old, $\mathrm{O}$, to the first object on the list. The mother, $\mathrm{L}$, leads the six year old, N, separately to visit another object. 
$\mathrm{L}$ and $\mathrm{N}$ are at object three, where $\mathrm{L}$ is reading out the text content to the son. $\mathrm{M}$, carrying $\mathrm{O}$, approaches the cabinet where object two is located (Fig. 7a).

L: Oh look, it says for $[N]$, from [O] (.) Shall we press the next one?

$M$ : ((Puts o down, Fig. 7b))

$L$ : Great. So we did that one (...) ((Turns to $M$, Fig. 7c)) I 1iked the music.

$\mathrm{N}$ : Where's the chess set?

L: We11, oh that's there so sha11 we go and do the other one and come back and do this one? Let's go and do the child's jacket. ((Guides $\mathrm{N}$ away to the adjacent room, Fig. 7d))
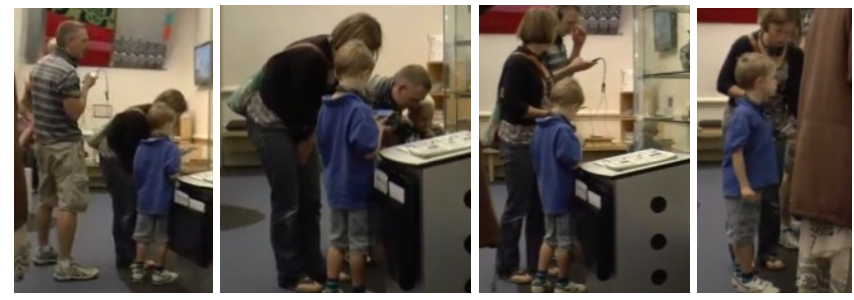

Figure 7: Two subgroups visiting different objects.

In this example, we again see interaction between those who are visiting objects in different orders (L saying "I liked the music" to $\mathrm{M}$ ). We then see $\mathrm{L}$ deciding to deviate from the order $\mathrm{N}$ is expecting ("where's the chess set?"), explaining that they will come back to visit that object. In our interview with this family it emerged that the two parents chose to separate into subgroups so they could take responsibility for a child each.

\section{Drifting apart}

There were some groups that didn't seem to explicitly decide whether to stay together or split up, but that moved between states of being in and out of sync.

Example 5: Group 3. Our final example looks at a group of four friends from an art appreciation group. They start the experience together and visit the first object, a wax sealing fob. They arrange themselves in two pairs (see Fig. 8a) and, after listening to the audio, one pair confers while the other pair moves on to the next object in the display case behind. By the time the second pair reaches the second object, a decorative drinking glass, the first pair has started the experience. The first pair separate to make room for the second pair to access the object (Fig. 8b), reforming the group of four. Another conversation breaks out between a new pairing, and the other two move on to the third object, in the same cabinet. After visiting the third object, one of the women scrolls through the list of objects on her device and chooses a later one, then walks towards the cabinet in which it is found. As the group is still within close proximity to each other (within line of sight) they continue to converse despite not visiting the same objects.
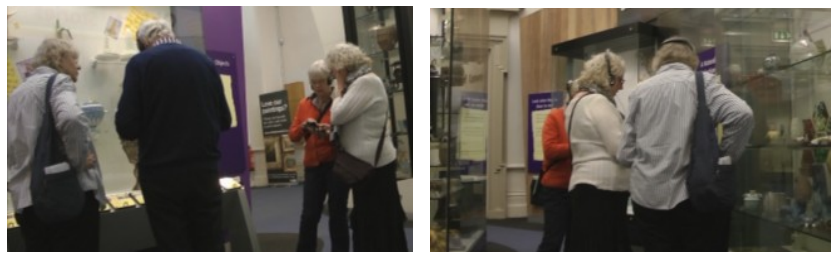

Figure 8: a) Group arranged in two pairs, and b) reuniting.

\section{DISCUSSION}

Our findings paint a picture of a shared visiting experience in which small groups of family and friends, including those with young children, systematically engaged with museum content. By and large, our groups invested significant effort in designing experiences for one another and 'saw these through' on returning to the museum, attempting and completing the vast majority of the content they had created. They created personalized interpretations which were frequently discussed and commented on during their visits. Moreover, the almost palpable sense of tension and embarrassment reported in Fosh's study of the asymmetric gifting of experiences among adults was notable by its absence here, with fewer intensely personal or provocative interpretations gifted between the friends and family who took part in our study, which seemed appropriate for an experience that is shared between small groups rather than couples. Visitors reported enjoying the experience and playfully engaging with and appreciating others' designs. Our findings also reveal an experience that accommodated diverse group behaviours from sticking together throughout to splitting up and rejoining and from pre-formulated strategies to ad-hoc coordination. These observations stand in marked contrast to Tolmie's study of group museum visiting that highlighted the ongoing tension of balancing engagement with content with paying attention to fellow group members. We now relate our observations to three broader themes in an attempt to both explain and generalize them.

\section{From museum artifacts to social objects}

In discussing participatory museum visiting, Nina Simon defines social objects as those that are "transactional, facilitating exchanges among those who encounter them" [25]. Such exchanges include discussions of an event or story the object brought to mind or cooperation around an object that invites play or touch. Our approach directly embeds social transactions into the mobile technology by having visitors design structured experiences around individual artifacts from instructions, music and information. This enables visitors to directly embed such transactions into the visit through the content they design for others - using music that represents a theme or memory, drawing attention to particular aspects of an artifact or taking it as inspiration for telling a story. At the very least, it allows visitors to draw their group members' attention to an object. We saw how visitors drew on their knowledge of each other and their inter-personal relationships to create social objects. When visitors experienced artifacts together, 
they often built upon the experience by responding or exchanging remarks, as in examples 1 and 2 . Even those visitors who split up to visit individually were able to discuss the experiences when they crossed paths or sought each other out (Example 3).

Moreover, our approach draws on an especially powerful form of social transaction - the gift. As Fosh et al. have previously argued, framing the design of experiences as gift-giving creates a strong social obligation for the recipient of the gift to complete the experience [18] and to respond appropriately [24]. In our study, we saw the hallmarks of gift-giving play out amongst the visitors, who recognized and appreciated when a gift had been tailored towards them, and who often commented on who the gift had been intended for, offering thanks and assessments.

Fosh et al. also noted potential anxiety and even embarrassment that arose when such gifts were given asymmetrically between pairs of visitors. This led us to extend the approach in three ways, each of which appear to have alleviated such tensions. The first has been to make them reciprocal. The approach reported here involves each member of a group designing for each other member. Each gives and receives, sharing the inherent risk of giving while also providing all concerned with opportunities for acknowledging and appreciating. The second has been to scale up beyond pairs. Mauss describes how gift-giving is socially occasioned and how gifts are 'opened' and appreciated in front of others who in turn play a role in appreciating them, an idea that is directly reflected in our approach. The third is to make them mutually pseudonymous, that is not directly associated with identified gift givers or giftees. By only revealing who each interpretation had been designed for and by at the end of each experience at an artifact, visitors may have been committed to see through the experience to find out if it had been intended for them. We also saw participants trying all the designs, rather than just those made for themselves or by specific people, perhaps motivated to find out if it had been intended for them. This meant all visitors in the group engaged with the same content. In addition, visitors who weren't sticking together were therefore aware of what everyone else was experiencing, allowing for discussion when they did come into contact.

In light of this discussion, we recommend the general approach of 'socializing' museum artifacts by getting visitors to craft and gift interpretations for one another. Our experience here suggests that such gifts should be reciprocal, exchanged incognito and exchanged among small groups. We also note that this approach is directly and easily implementable in software, with the gift-giving transactions being realized in simple templates.

\section{From directed to scaffolded experiences}

Previous studies of museum visitors have uncovered a range of different visiting styles and have attempted to categorize visitors into different types that may change throughout the visit [26, 29]. Early categorizations focused on individual visitors, but the idea of classification has since been extended to pairs of visitors based on their engagement and orientation towards each other and exhibits [16]. The dynamics of visiting as a family group have also been well documented, with studies revealing the extreme prevalence of playful behavior with interactives and long conversations among the group [19], and the impact of parents' shaping and supporting of children's interactions on learning [7]. Previous responses to such observations have aimed to augment social interaction in museum visiting by promoting connection with others [5] and engaging group members in a coordinated narrative to induce group conversation [4], the latter being unusual in narrative-driven directed experiences in that it required collaboration for the story to unfold.

Our study suggests that an open and flexible structure can accommodate a range of different visiting styles. While each bite-sized experience of an individual artifact was highly directed through instructions, music and information, there was no overarching narrative that needed to be followed to connect them altogether. While visitors chose experiences from an ordered list, the order was not enforced or strongly narrativised. Nor were there any requirements to collaborate in order to progress. Visitors were therefore free to manage the overall global trajectory of their visit as they saw fit, splitting and joining according to local needs and circumstances. Thus, around half of the groups $(1,5,7,9$, 10 and 11) stuck together during their visits, while the others split up to some degree. We found that sticking together generally involved joint decision making, waiting for one another, and discussing interpretations in the moment: what might be thought of as an ideal social visit. However, we were also able to observe behaviors in those who split up that suggested a level of social engagement despite group members not visiting objects synchronously. This took the form of visitors finding themselves coinciding at the same object and sharing a more spontaneous engagement, seeking one another out to give feedback or seek assessment, or monitoring one another from afar.

Another notable feature of our approach is its technical simplicity. There are no location-based technologies at play here, no recommender systems or triggering of content and no attempt to technically synchronize content between people. Rather, visitors must author and then select experiences for themselves, find the artifacts involved using conventional means and then manually trigger the 'content' (manually synchronized if they so wish). The approach balances orchestration of the experience with visitors' own agency; by scaffolding rather than directing, we encourage visitors to carve their own trajectories through the experience, rather than designing for a canonical way of visiting [3]. This is a common approach in visiting experiences with mediascapes [14] and participatory performance [27]. This manual approach to scaffolding rather than directing experiences even extends to the use of 
headphones (traditionally a thorny issue in mobile CSCW systems $[1,17])$ with visitors manually putting them on and taking them off as required. While clearly demanding more work of visitors, this largely manual approach does not appear to have caused difficulties or frustration and does appear to have afforded great flexibility for adapting to different visiting styles.

This scaffolding approach was perhaps most evident in enabling adults to support children when managing the family experience. Children were able to engage in the making and doing of experiences with support from their parents, listening to the music, dancing around and repeating experiences they had enjoyed. They sometimes surprised parents with thoughtful designs and questions. And yet, it was also possible to mix in moments of experience for adults in the party too.

In light of these observations, we recommend experience designers to recognize that sometimes 'less is more' and that approaches that scaffold interactions without heavily directing them (e.g., through strong narratives, collaborative mechanics, location-based wayfinding and triggers and so forth) have a valuable role to play in visiting experiences.

\section{From cohesive groups to coherent experiences}

Considering the nature of groups is both fundamental and challenging for $\mathrm{CSCW}$. One common approach is to consider physical collocation, drawing on notions of proxemics from anthropology [13] and employing locationbased technologies to detect collocated formations [23], sometimes in combination with the strength of socialnetwork connections [20]. Another key idea is that of the cohesiveness of groups working together on tasks, that is, on the strength of social relationships between those working together and the effects of this on the quality of their work [22].

Groups in leisure activities, such as museum visiting, are likely to already enjoy strong social relationships and therefore to exhibit tight cohesiveness as a group. Indeed, this very cohesiveness may be a major challenge for museum experience designers as they seek to engage tightly-knit groups with their content rather than with each other. This tension between group cohesion and external content lies at the heart of Tolmie's previous observations of museum studies, leading him to discuss the notion of group coherence that involves maintaining a level of togetherness through staying within line of sight [28]. This, and other forms of awareness of group members' activities, has been shown to be important in collocated collaboration [32].

Our study revealed how some visitors intentionally avoided being in physical proximity to each other, using their awareness of others' location to avoid going in the same direction. Others appear to drift in and out of awareness without any noticeable detriment or premature disengagement with exhibits in order to maintain an overall coherence. It seems, then, that these visitors were unfazed by the potential incoherence of their group visit in a way that the groups in Tolmie et al.'s study went to some lengths to avoid. When they did engage with one another, sporadically, inadvertently or intentionally, they were able to discuss the experience and engage with each other, before possibly splitting up again.

Our findings suggest that perhaps group cohesion and coherence in museum visiting are not as straightforward as previously thought. Groups were able to engage fully with our experience despite not always being physically proximate or within line of sight. Having a shared set of content, that was generated through reflecting on the group's social relationships, and knowing the experience was limited to the list of objects they all shared, appeared to break down the need to be constantly aware of each other's whereabouts. Coherence might then be better thought of as a more esoteric property that comes about as a result of tight social cohesiveness (the groups were existing friends or family), being focused on the same task (all group members were engaging with, and invested in, the visiting experience), and some kind of spoken or unspoken agreement about how closely they would stay together during the visit (some visitors announced their plans to visit separately while others did not). Furthermore, the notion of coherence might be extended to encompass the entire experience rather than the state of the participants at any one moment. It may not matter if visitors temporarily split up if the wider nature of their experience is sufficiently coherent that they are comfortable that they will soon be able to rejoin.

\section{CONCLUSIONS, LIMITATIONS AND FUTURE WORK}

Tolmie's previous ethnographic study of two major museums revealed the significant problems facing both visitors and curators as groups of visitors struggled to balance their engagement with exhibits with the need to attend to one another - often to the detriment of the former. In response, we have demonstrated how the previously proposed approach of gifting experiences can be extended through reciprocity and concealed identity - to potentially mitigate these problems and deliver a group visiting experience that engages groups with content while remaining flexible to how they organize themselves locally. However, it is important to note several limitations of our study that need to be considered and addressed in future work before we can fully understand whether this approach can be successful and also how it might best be applied.

First, we have not undertaken a controlled study to compare our approach with others and so need to be careful with any claims to success compared to the current visiting experience or other approaches. Having said this, the curators we engaged with at our museum setting reported that the rooms in which we worked were notable as being their most problematic in terms of engagement with exhibits for groups. Tolmie's study revealed the common 
challenges of group visiting over many groups in two different museums, albeit ones that were larger in scale and complexity and also more crowded. Moreover, our participants were clearly taking part in a research study and so may well have behaved more coherently as a result. It is important to deploy our approach naturally 'in the wild' in future work, and to allow for different types of group beyond families and close friends, who may well behave differently.

Our approach requires participants to engage significant effort at the design stage, raising questions as to whether they will be willing to do this and also how would it scale to large numbers of exhibits and/or visitors. Future work needs to explore how visitors can be supported in readily creating experiences from templates, for example through an online service. How can the design stage as well as the visit stage be scaffolded? Will it be acceptable or useful to share designs more publicly as inspiration to others?

Given these caveats, we do not claim our approach as a panacea for designing group visits to museums. Indeed, although we positioned it as something of an alternative to more directed approaches earlier on, we foresee that it might ultimately be combined with these as part of the curator's armory of techniques and technologies. Perhaps gifted experiences will form only a part of an overall visit, applying to a few selected artifacts, or perhaps they will be for special visitors or occasions (a birthday treat?). Gifting may fit repeat visits, with those who have experienced the museum being able to design experiences for family or friends? And perhaps gifting templates need to be combined with other technologies such as recommender systems to help people design their gifts? To conclude, then, we suggest that our study confirms the initial promise of the gifting approach, at least to support small-group visits, but that many questions remain open for further exploration.

\section{ACKNOWLEDGMENTS}

Lesley Fosh is supported by the Horizon Centre for Doctoral Training at the University of Nottingham (RCUK Grant No. EP/G037574/1). This work was also supported by the Platform Grant award EP/FO3038X/1.

\section{REFERENCES}

1. Paul M. Aoki, Rebecca E. Grinter, Amy Hurst, Margaret H. Szymanski, James D. Thornton, Allison Woodruff. 2002. Sotto voce: exploring the interplay of conversation and mobile audio spaces. In Proceedings of the SIGCHI Conference on Human Factors in Computing Systems (CHI '02), 431-438.

http://doi.acm.org/10.1145/503376.503454

2. Appfurnace Website. 2015. http://appfurnace.com.

3. Steve Benford, Gabriella Giannachi, Boriana Koleva, Tom Rodden . 2009. From Interaction to Trajectories: designing coherent journeys through user experiences. In Proceedings of the SIGCHI Conference on Human Factors in Computing Systems (CHI '09), 709-718. http://doi.acm.org/10.1145/1518701.1518812

4. Charles Callaway, Oliviero Stock, Elyon Dekoven, Kinneret Noy, Yael Citron, Yael Dobrin. 2011. Mobile Drama in an Instrumented Museum: Inducing Group Conversation via Coordinated Narratives. In Proceedings of the 16th International Conference on Intelligent User Interfaces (IUI '11), 73-82. http://doi.acm.org/10.1145/1943403.1943416

5. Dan Cosley, Joel Lewenstein, Andrew Herman, Jenna Holloway, Jonathan Baxter, Saeko Nomura, Kirsten Boehner, Geri Gay. 2008. ArtLinks: fostering social awareness and reflection in museums. In Proceedings of the SIGCHI Conference on Human Factors in Computing Systems (CHI '08), 403-412. http://doi.acm.org/10.1145/1357054.1357121

6. Andy Crabtree, Alan Chamberlain, Rebecca E. Grinter, Matt Jones, Tom Rodden, Yvonne Rogers. 2013. Introduction to the Special Issue of "The Turn to The Wild". Transactions on Computer-Human Interaction. 20, 3, 4 pages. http://doi.acm.org/ 10.1145/2491500.2491501

7. Kevin Crowley, Maureen A. Callanan, Jennifer L. Jipson, Jodi Galco, Karen Topping and Jeff Shrager. 2001. Shared scientific thinking in everyday parent-child activity. Science Education. 85, 6, 712732. http://dx.doi.org/10.1002/sce.1035

8. John H Falk and Lynn D Dierking. 1992. The Museum Experience, Whalesback Books, Washington.

9. Lesley Fosh, Steve Benford, Stuart Reeves, Boriana Koleva, and Patrick Brundell. 2013. See Me, Feel Me, Touch Me, Hear Me: Trajectories And Interpretation In A Sculpture Garden. In Proceedings of the SIGCHI Conference on Human Factors in Computing Systems (CHI'13), 149-158. http://doi.acm.org/10.1145/2470654.2470675

10. Lesley Fosh, Steve Benford, Stuart Reeves, and Boriana Koleva. 2014. Gifting Personal Interpretations in Galleries. In Proceedings of the SIGCHI Conference on Human Factors in Computing Systems (CHI '14), 625634. http://doi.acm.org/10.1145/2556288.2557259

11. Geller, T. (2006). Interactive tabletop exhibits in museums and galleries. Computer Graphics and Applications. 26, 5, 6-11. http://dx.doi.org/10.1109/MCG.2006.111

12. Rebecca E. Grinter, Paul M. Aoki, Margaret H. Szymanski, James D. Thornton, Allison Woodruff, Amy Hurst. 2002. Revisiting the visit: understanding how technology can shape the museum visit. In Proceedings of the ACM conference on Computer Supported Cooperative Work (CSCW '02), 146-155. http://doi.acm.org/10.1145/587078.587100

13. Edward T. Hall. 1966. The Hidden Dimension. Anchor Books.

14. Adrian Hazzard, Steve Benford, Gary Burnett. 2015. Sculpting a Mobile Musical Soundtrack. In Proceedings of the SIGCHI Conference on Human Factors in Computing Systems (CHI '15), 387-396. 
http://doi.acm.org/10.1145/2702123.2702236

15. Tom Hope, Yoshiyuki Nakamura, Toru Takahashi, Atsushi Nobayashi, Shota Fukuoka, Masahiro Hamasaki, Takuichi Nishimura. 2009. Familial collaborations in a museum. In Proceedings of the SIGCHI Conference on Human Factors in Computing Systems (CHI '09), 1963-1972. http://doi.acm.org/10.1145/1518701.1519000

16. Tsvi Kuflik and Eyal Dim. 2013. Early Detection of Pairs of Visitors by Using a Museum Triage. In Museums and the Web 2013, N. Proctor \& R. Cherry (eds). Silver Spring, MD.

17. David Martin. 2002. Audio Guides. Museum Practice. $5,1,71-81$.

18. Marcel Mauss. 1990. The gift: the form and reason for exchange in archaic societies. London: Routledge Classics.

19. Paulette M. McManus. 1987. It's the company you keep...: The social determination of learning-related behaviour in a science museum. Museum Management and Curatorship. 6, 3, 263-270.

20. Sanjay Purushotham, C.-C. Jay Kuo, Junaith Shahabdeen, Lama Nachman. 2014. Collaborative Group-Activity Recommendation in Location-Based Social Networks. In Proceedings of the SIGSPATIAL International Workshop on Crowdsourced and Volunteered Geographic Information, 8-15. http://doi.acm.org/10.1145/2676440.2676442

21. Jessica S. Robles. 2012. Troubles with assessments in gifting occasions, Discourse Studies. 14, 6, 753-777.

22. Victoria L. Schwanda, Kyle Barron, Jennifer Lien, Gretchen Schroeder, Ashley Vernon, Jeffrey $T$. Hancock. 2011. Temporal Patterns of Cohesiveness in Virtual Groups. In Proceedings of the ACM Conference on Computer Supported Cooperative Work (CSCW '11),709-712. http://doi.acm.org/10.1145/1958824.1958951

23. Rijurekha Sen, Youngki Lee, Kasthuri Jayarajah, Archan Misra, Rajesh Krishna Balan 2014. GruMon: Fast and Accurate Group Monitoring for Heterogeneous Urban Spaces. In Proceedings of the 12th ACM
Conference on Embedded Network Sensor Systems (SenSys '14), 46-60. http://doi.acm.org/10.1145/2668332.2668340

24. John F. Sherry Jr. 1983. Gift giving in anthropological perspective. Journal of Consumer Research 10(2). 157168.

25. Nina Simon. 2010. The Participatory Museum. Museums 2.0.

26. Flavia Sparacino. 2002. The Museum Wearable: RealTime Sensor-Driven Understanding of Visitors Interests for Personalized Visually-Augmented Museum Experiences. In Museums and the Web 2002, N. Proctor \& R. Cherry (eds). Silver Spring, MD.

27. Robyn Taylor, Guy Schofield, John Shearer, Peter Wright, Pierre Boulanger, and Patrick Olivier. 2014. Nightingallery: Theatrical Framing and Orchestration in Participatory Performance. Personal Ubiquitous Computing. 18, 7, 1583-1600.

28. Peter Tolmie, Steve Benford, Chris Greenhalgh, Tom Rodden, Stuart Reeves. 2014. Supporting Group Interactions in Museum Visiting, In Proceedings of the ACM Conference on Computer Supported Cooperative Work (CSCW'14), 1049-1059. http://doi.acm.org/10.1145/2531602.2531619

29. Eliseo Véron and Martine Levasseur. 1989. Ethnographie de l'exposition: l'espace, le corps et le sens, Centre Georges Pompidou, Bibliothèque publique d'information.

30. Dirk vom Lehn, Christian Heath and Jon Hindmarsh. 2001. Exhibiting interaction: Conduct and collaboration in museums and galleries. Symbolic Interaction. 24, 2, 189-216.

31. David B. Wooten. 2000. Qualitative Steps toward an Expanded Model of Anxiety in Gift-Giving. Journal of Consumer Research. 27, 1, 84-95.

32. Nicola Yuill and Yvonne Rogers. 2012. Mechanisms for Collaboration: A Design and Evaluation Framework for Multi-User Interfaces. Transactions on ComputerHuman Interaction. 19, 1, 25 pages. http://doi.acm.org/10.1145/2147783.2147784 